\title{
Flax Seed Mucilage-chitosan Polyelectrolyte Complex Nanoparticles: Optimization, Characterization and Evaluation
}

\author{
Meenakshi Bhatia ${ }^{1 *}$, Sunidhi Lohan ${ }^{1}$ \\ 1 Guru Jambheshwar University of Science and Technology, Department of Pharmaceutical Sciences Hisar, India.
}

\begin{abstract}
The aim of this study is to prepare flaxseed mucilage (FSM) and chitosan polyelectrolyte complex (PEC) nanoparticles by ionic gelation method for developing sustained release formulation. For the formation of PEC nanoparticles, the water extract of flax seed is obtained by soaking the seeds in water overnight followed by precipitation with ethanol and washing with distilled water.FSM was interacted with fully protonated chitosan (in acetic acid $2 \% \mathrm{v} / \mathrm{v}$ ) using Isonicotinylhydrazide (INH) as a model drug. The results of optimization study reveals that lower level of chitosan and flaxseed mucilage favors the lowest particle size.The optimum quantum of FSM and chitosan were found to be $0.011 \%(\mathrm{w} / \mathrm{v})$ and $0.011 \%(\mathrm{w} / \mathrm{v})$ respectively, that produced nanometric particles of size $326 \mathrm{~nm}$ with poly-dispersity index (PdI) of 0.217. The in vitro release profile of INH from the optimized batch was determined using the dialysis sac and it was found that INH get released over a prolonged period of 20 hours following Higuchi's square root release kinetics with the combination of diffusion and erosion of matrix as release mechanism. It can be concluded from the present study that interaction between chitosan and FSM can be used for the formation of PEC nanoparticles and for developing sustained release formulation.
\end{abstract}

Keywords: Flaxseed, chitosan, polyelectrolyte, complex, nanoparticles.

\section{INTRODUCTION}

Flax (Linum usitatissimum), also known as common flax or linseed consists of the dried fully ripe seeds of the genus Linum belonging to family Linaceae ${ }^{1}$. Chemically, it contains d-galacturonic acid, l-rhamnose, l-galactose, and dxylose. It is gluten free and also rich in omega-3, omega-6, a-linolenic acid, lignans, high quality proteins and fibers. The flax seed mucilage has been widely

${ }^{*}$ Corresponding Author: Meenakshi Bhatia, e-mail: meenaxibhatia@gmail.com

Meenakshi Bhatia ORCID Number: 0000-0003-4568-7582

Sunidhi Lohan ORCID Number: 0000-0002-2085-8720

(Received 15 March 2019, accepted 20 May 2019) 
explored in traditional herbal remedies, food and pharmaceutical industry. Flaxseed is a multi component system containing biologically-active plant substances like dietary fiber, oil, protein, soluble polysaccharides, phenolic compounds, minerals, vitamins and lignans ${ }^{2}$. It also contains water soluble and insoluble fibers. Insoluble fibers help in improving laxation and preventing constipation, chiefly by increasing fecal mass and lowering bowel transit time $^{3}$. Moreover, water-soluble fibers helps in maintaining glucose levels and lowering the cholesterol levels in blood ${ }^{4}$. Flax lignans is known to be effective in reducing the growth of particularly hormone sensitive cancerous tumors, such as those of the breast, endometrium and prostates. Flaxseeds were also used as medicines since immemorial times to relieve the abdominal pain and as cough remedy. Flaxseeds possess significant health benefits besides the nutrition due to high content of $\omega-3 \alpha$-linolenic acid and of lignans having antioxidant properties ${ }^{2}$.

Chitosan (CS) is commonly obtained from deacetylated (D-glucosamine) derivative of chitin, a cationic polysaccharide. It has already been explored for formulating nanoparticles with polyanions by ionotropic gelation method ${ }^{6}$. The complexes of chitosan with polyanions have been screened in effectively limiting the release of entrapped drug as compared to the polyanion or chitosan alone. PEC nanoparticles of chitosan with psyllium arabinoxylan', hyaluronic acid $^{8}$, carboxymethyl gum kondagogu ${ }^{9}$, carboxymethyl amylopectin ${ }^{10}$, gum ghatti ${ }^{11}$ and sodium alginate ${ }^{12}$ have been reported in literature. Isonicotinylhydrazide (INH) is an antibiotic that is used in the treatment of tuberculosis ${ }^{13}$. It is used in combination with other tuberculosis drugs to prevent the development of drug resistance and also act as bactericidal and bacteriostatic drug. It also acts as a source of free radicals by inhibiting the cytochrome $\mathrm{P} 450$ system. The solubility of INH in water is $125 \mathrm{mg} / \mathrm{ml}$ at room temp. It is on the border line of BCS Class I \&III ${ }^{14}$. In this piece of research work PEC nanoparticles of CS-FSM were prepared by ionotropic gelation method using INH as a model drug. The PEC nanoparticles was characterized by fourier-transform infra-red spectroscopy, X-ray diffraction analysis, thermo gravimetric analysis and scanning electron microscopy. The interaction of Chitosan-FSM in preparing PEC nanoparticles was optimized by using two-factor, three-level central composite experimental design. In-vitro release behaviour of drug INH from the optimised batch of PEC nanoparticles was evaluated by release rate study.

\section{METHODOLOGY}

Flax seeds were purchased from Patanjali mega store, Hisar, India. Chitosan was purchased from Sisco Research Laboratories Pvt. Ltd. Mumbai, India. 
Isonicotinylhydrazide (INH) was generously provided as a gift sample from Aventis Pharma Ltd (Ankleshwar, India). All other chemicals like ethanol and acetic acid (SD Fine Chemical Ltd.) used in this study were of analytical grade and utilised as received.

\section{Isolation of flaxseed mucilage}

The water extract of flax seed was obtained by soaking the seeds in distilled water (1:50) overnight. The insoluble fraction was removed by passing it through the muslin cloth. To isolate the mucilage, equal volume of ethanol was added for precipitation under continuous stirring. The separated mucilage is then washed with distilled water and collected through filtration by muslin cloth. The mucilage so obtained was kept at $-80^{\circ} \mathrm{C}$ for $4 \mathrm{~h}$ followed by lyophilization in a laboratory model freeze drier at $-90^{\circ} \mathrm{C}$ under a pressure of 0.0010 mbar for $24 \mathrm{~h}$.

\section{Preparation of flaxseed mucilage-chitosan PEC nanoparticles}

FSM was interacted with fully protonated chitosan (in acetic acid $2 \% \mathrm{v} / \mathrm{v}$ ) using INH as a model drug for the preparation of PEC nanoparticles. Aqueous chitosan solutions were prepared in acetic acid ( $2 \% \mathrm{w} / \mathrm{v})$ under stirring while aqueous solutions of FSM were prepared by adding the required quantity of FSM as per the design protocol in distilled water followed by stirring. The polyelectrolyte complex nanoparticles of FSM-CS were prepared by drop wise addition of aqueous solution of CS (0.010 to $0.020 \% \mathrm{w} / \mathrm{v}$ ) containing INH (50 \% of the total polymer weight) to the aqueous solution of FSM (0.010 to $0.020 \%$ $\mathrm{w} / \mathrm{v}$ ) under strong agitation at room temperature ${ }^{7}$.

\section{Experimental design}

The preparation of FSM-CS polyelectrolyte nanoparticles was optimised using 2-factor,3-level central composite experimental design (Table I). It was discerned from the preliminary trials that concentration of FSM and CS affect the p-size, polydispersity index (PdI) and entrapment efficiency. Therefore, the concentration of chitosan $\left(\mathrm{X}_{1}\right)$ and FSM $\left(\mathrm{X}_{2}\right)$ were taken as the formulation variables whereas particle size $\left(\mathrm{Y}_{1}\right), \mathrm{PdI}\left(\mathrm{Y}_{2}\right)$ and entrapment efficiency $\left(\mathrm{Y}_{3}\right)$ were selected as response variables. Each of the independent variable was investigated at three levels (i.e. $-1,0,+1)$. Design Expert software (Version 11.0) was used for the experimental design and statistical analysis of data 7 
Table 1. Particle size, Pdl and entrapment efficiency of different batches of CS-FSM polyelecrolyte complex nanoparticles.

\begin{tabular}{|c|c|c|c|c|c|}
\hline Batch & $\begin{array}{c}\text { Conc. of } \\
\text { chitosan } \\
(\%, w / v)\left(X_{1}\right)\end{array}$ & $\begin{array}{c}\text { Conc. of } \\
\text { FSM } \\
(\%, w / v)\left(X_{2}\right)\end{array}$ & $\begin{array}{c}\text { P- size } \\
(\mathrm{d}-\mathrm{nm}) \\
\left(\mathrm{Y}_{1}\right)\end{array}$ & $\begin{array}{l}\text { Pdl } \\
\left(Y_{2}\right)\end{array}$ & $\begin{array}{c}\text { Entrapment } \\
\text { efficiency } \\
(\%) \\
\left(\mathrm{Y}_{3}\right)\end{array}$ \\
\hline Batch & $\begin{array}{c}\text { Conc. of } \\
\text { chitosan } \\
(\%, w / v)\left(X_{1}\right)\end{array}$ & $\begin{array}{c}\text { Conc. of } \\
\text { FSM } \\
(\%, w / v)\left(X_{2}\right)\end{array}$ & $\begin{array}{c}\text { P- size } \\
(\mathrm{d}-\mathrm{nm}) \\
\left(\mathrm{Y}_{1}\right)\end{array}$ & $\begin{array}{l}\mathrm{Pdl} \\
\left(\mathrm{Y}_{2}\right)\end{array}$ & $\begin{array}{c}\text { Entrapment } \\
\text { efficiency } \\
(\%) \\
\left(\mathrm{Y}_{3}\right)\end{array}$ \\
\hline 1 & 0.015 & 0.015 & 425 & 0.312 & 87.5 \\
\hline 2 & 0.015 & 0.010 & 377 & 0.256 & 87.3 \\
\hline 3 & 0.010 & 0.015 & 350 & 0.249 & 87.0 \\
\hline 4 & 0.010 & 0.010 & 327 & 0.230 & 85.2 \\
\hline 5 & 0.015 & 0.020 & 413 & 0.391 & 88.9 \\
\hline 6 & 0.015 & 0.015 & 442 & 0.307 & 87.8 \\
\hline 7 & 0.015 & 0.015 & 456 & 0.289 & 86.8 \\
\hline 8 & 0.010 & 0.020 & 372 & 0.235 & 85.7 \\
\hline 9 & 0.020 & 0.020 & 712 & 0.472 & 92.0 \\
\hline 10 & 0.015 & 0.015 & 468 & 0.338 & 87.2 \\
\hline 11 & 0.020 & 0.015 & 565 & 0.464 & 91.0 \\
\hline 12 & 0.020 & 0.010 & 532 & 0.391 & 89.0 \\
\hline 13 & 0.015 & 0.015 & 481 & 0.374 & 86.7 \\
\hline
\end{tabular}

\section{Characterization of flaxseed mucilage and chitosan PEC nanoparticles:}

The polyelectrolyte complex nanoparticles of flaxseed mucilage-chitosan containing INH drug were characterised by Fourier transform infra-red spectroscopy (FT-IR), Differential scanning calorimeter (DSC), Powder X-ray diffraction analysis (PXRD) and Scanning electron microscopy (SEM) studies and further evaluated for particle size $(\mathrm{d}, \mathrm{nm})$, polydispersity index (PdI), and drug entrapment efficiency.

\section{Particle size analysis}

Average particle size and polydispersity index (PdI) of nanoparticles was measured by using Zetasizer (Nano ZS9o, Malvern Instrument, UK). The measurements were done in automated mode at $25^{\circ} \mathrm{C}$ after equilibrating for $120 \mathrm{~s}$. 


\section{Entrapment efficiency}

The amount of drug entrapped in nanoparticles was calculated by separating the unentrapped drug by centrifuging the sample at $15000 \mathrm{rpm}$ for $40 \mathrm{~min}$ by cooling centrifuge (C-24 BL, Remi Instruments, and Mumbai, India). The supernatant was analyzed for the contents of unentrapped INH by measuring the absorbance at $262 \mathrm{~nm}$ in a UV-Vis spectrophotometer (Cary 5000, Varian Australia). The entrapment efficiency (\%) was calculated as follows:

Where, $I N H_{t}$ is the total amount of isoniazid used in the preparation of polyelectrolyte complex nanoparticles and INHs is the unentrapped isoniazid present in the supernatant.

\section{Fourier transform infra-red spectroscopy (FT-IR)}

FSM-CS PEC nanoparticles were subjected to FT-IR spectroscopy in a FTIR spectrophotometer (Perkin-Elmer, Spectrum, US) in range of $4000 \mathrm{~cm}^{-1}$ to 400 $\mathrm{cm}^{-1}$ using $\mathrm{KBr}$ pellet method, to detect interaction between drug and polymer.

\section{Powder X-ray diffraction analysis (PXRD)}

Powder X-ray diffraction analysis was carried out to study the structure, composition and physical properties of samples. The CS, FSM, INH and PEC powder samples were examined using an X-ray diffractometer (Miniflex 2, Rigaku, Japan) from $o^{\circ}$ to $80^{\circ}$ diffraction angle $(2 \Theta)$ range under the following measurement conditions: source, nickel filtered $\mathrm{Cu}-\mathrm{K}$ a radiation; voltage $30 \mathrm{kV}$; current $25 \mathrm{~mA}$; scan speed $0.05 \mathrm{~min}-1$, division slit $1.25^{\circ}$, receiving slit 0.3 $\mathrm{mm}$.

\section{Differential scanning calorimeter}

Differential scanning calorimetric analysis was carried out to confirm the physical state and purity of the samples. The DSC of CS, FSM, INH and PEC were carried out in the temp. range of $25^{\circ} \mathrm{C}$ to $250^{\circ} \mathrm{C}$ under constant nitrogen purge of $100 \mathrm{ml} / \mathrm{min}$ with heating rate of $10^{\circ} \mathrm{C}$ per minute using DSC (Perkin Elmer USA).

\section{Scanning electron microscopy}

The surface and shape of the polyelectrolyte complex was examined using scanning electron microscopy. The sample was mounted using double sided adhesive tape on metal grids and coated with gold under vacuum prior to observation. 


\section{In-vitro drug release study}

The drug release from the optimized batch formulation and drug solution was determined using dialysis sac method using USP-II dissolution apparatus. An accurately measured volume of nanoparticles $(5 \mathrm{ml})$ and equivalent amount of drug solution were placed in the dialysis tubing (cut off 10,00o kDa) separately. The dialysis tubing was tied up to the paddle of USP type II dissolution apparatus (TDL-08L, Electro lab, India) and immersed in $300 \mathrm{ml}$ of dissolution fluid (phosphate buffer $\mathrm{pH}$ 7.4). The temp. of dissolution media was maintained at $37^{\circ} \mathrm{C} \pm 0.5^{\circ} \mathrm{C}$ with continuous stirring at $50 \mathrm{rpm}$. An aliquot of $5 \mathrm{ml}$ sample was withdrawn at various time intervals and the media volume was maintained by replacing equal volumes of fresh media i.e. buffer $\mathrm{pH}$ 7.4. The concentration of INH in the samples was determined in UV-visible spectrophotometer by measuring absorbance at $262 \mathrm{~nm}$. The release data was then fitted into various release kinetic models to estimate the kinetic and mechanism of release.

\section{RESULTS AND DISCUSSION}

CS-FSM PEC nanoparticles prepared by ionic gelation method were optimized using 2-factor,3-level central composite design (Design expert version 11.0) and characterized by FTIR, DSC, XRD and SEM studies. The in-vitro release pattern of optimized batch was estimated using USP type II dissolution apparatus using dialysis sac.

Figure 1 exhibits the FT-IR spectra of PEC, CS, INH, and FSM respectively in the frequency range of $4000-400 \mathrm{~cm}^{-1}$. The spectra of CS show a broad absorption band at $3422.04 \mathrm{~cm}^{-1}$ which may be attributed to -OH stretching of alcohols. The peak appearing at $2874.61 \mathrm{~cm}^{-1}$ can be ascribed to $-\mathrm{CH}$ stretch of alkanes, while the peak at $2145.70 \mathrm{~cm}^{-1}$ is due to $-\mathrm{C} \equiv \mathrm{C}-$ stretch of alkynes, whereas peak at $1602.93 \mathrm{~cm}^{-1}$ is due to $-\mathrm{NH}$ bending whereas peaks at 1420.62 $\mathrm{cm}^{-1}$ and $1384.11 \mathrm{~cm}^{-1}$ are due to $-\mathrm{CH}$ bending of alkanes. The spectra of FSM exhibit a broad absorption band at $3423.63 \mathrm{~cm}^{-1}$ is due to $-\mathrm{OH}$ stretching of alcohols. The peak appearing at $2933 \mathrm{~cm}^{-1}$ is due to $-\mathrm{CH}$ stretching of alkane, while the peaks appearing at $2345.45 \mathrm{~cm}^{-1}$ and $2364.71 \mathrm{~cm}^{-1}$ may be ascribed to $-\mathrm{CH}$ stretch of alkane. The peaks at $1618.03 \mathrm{~cm}^{-1}$ and $1420.42 \mathrm{~cm}^{-1}$ are due to $-\mathrm{NH}$ bending and $-\mathrm{CH}$ bending, respectively. The spectra of pure drug INH shows a sharp absorption peak at $3304.06 \mathrm{~cm}^{-1}$ due to presence of (-NH $)$ amine group and other peak at $3114.02 \mathrm{~cm}^{-1}$ is due to $-\mathrm{NH}$ stretch of amine group and other peak $-\mathrm{CH}$ on $2862.74 \mathrm{~cm}^{-1},-\mathrm{C}=\mathrm{O}$ stretch on $1666.53 \mathrm{~cm}^{-1},-\mathrm{NH}$ bending on $1602.55 \mathrm{~cm}^{-1}$ and $1556.24 \mathrm{~cm}^{-1}$ shows presence of amide group. Peak at $1411.93 \mathrm{~cm}^{-1}$ shows $-\mathrm{CH}$ bending of alkane, while peak at $1334.23 \mathrm{~cm}^{-1}$, $1221.32 \mathrm{~cm}^{-1}$ and $1141.62 \mathrm{~cm}^{-1}$ are due to $-\mathrm{CN}$ stretch of amine. The spectra of 
CS-FSM PEC displayed characteristic peak of drug at $1648 \mathrm{~cm}^{-1}$ that is attributed to amide carbonyl structure of hydrazide in PEC and the peak appearing at1087.02 $\mathrm{cm}^{-1}$ may be ascribed to $-\mathrm{CN}$ stretch of amine whereas peak appearing at $1024.20 \mathrm{~cm}^{-1}$ is due to $-\mathrm{C}-\mathrm{O}$ stretch of ether. The peaks at $889.87 \mathrm{~cm}^{-1}$ and $672.51 \mathrm{~cm}^{-1}$ are due to $=\mathrm{C}-\mathrm{H}$ bending of alkene appeared in PEC. The spectra of CS-FSM polyelectrolyte complex demonstrated a slight shift of the peak at $3292.27 \mathrm{~cm}^{-1}$ due to interaction between drug INH and carriers that confirms the formation of complex.

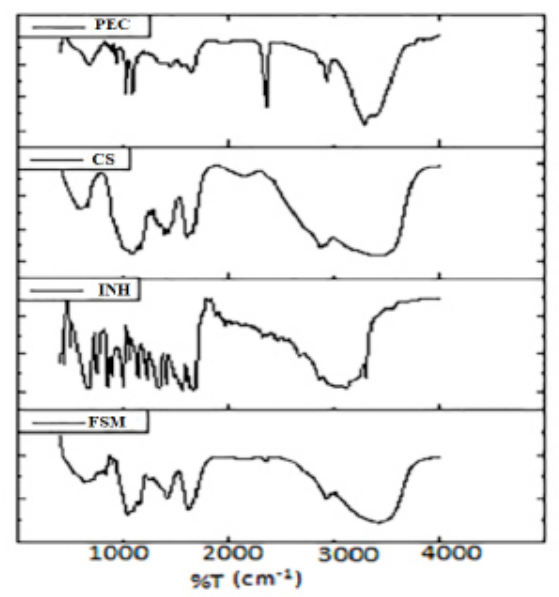

Figure 1. FT-IR spectra of PEC, CS, INH and FSM

Figure 2 represent the thermogram of differential scanning calorimetry (DSC) analysis of PEC, INH, FSM and CS. DSC of samples was carried out by heating the sample from room temperature to $250^{\circ} \mathrm{C}$ under constant nitrogen purge of $10 \mathrm{ml} / \mathrm{min}$ at a heating rate of $10^{\circ} \mathrm{C}$ per minute. The thermogram of INH shows sharp endothermic peak at $173.03^{\circ} \mathrm{C}$ that corresponds to its melting point, having AUC $45.0049(\mathrm{w} / \mathrm{g}){ }^{\circ} \mathrm{C}$ with heat of fusion of $232.62 \mathrm{~J} / \mathrm{g}$. The thermograms of FSM and CS are of typical amorphous material showing broad endothermic peak at $78.04^{\circ} \mathrm{C}$ and $75.92^{\circ} \mathrm{C}$ having AUC $105.767(\mathrm{w} / \mathrm{g}){ }^{\circ} \mathrm{C}$ and $64.0613(\mathrm{w} / \mathrm{g})$ ${ }^{\circ} \mathrm{C}$ and heat of fusion of $355.63 \mathrm{~J} / \mathrm{g}$ and $178.79 \mathrm{~J} / \mathrm{g}$, respectively. However, the thermogram of PEC shows two endothermic peaks at $150.95^{\circ} \mathrm{C}$ and $163.38^{\circ} \mathrm{C}$ with heat of fusion of $49.614 \mathrm{~J} / \mathrm{g}$ and $97.591 \mathrm{~J} / \mathrm{g}$ respectively. There is a disappearance of broad endotherm and a shift in the endothermic peak with decreased intensity is noticed that indicates that modification has been taken place in the formation of electrolyte complex. 


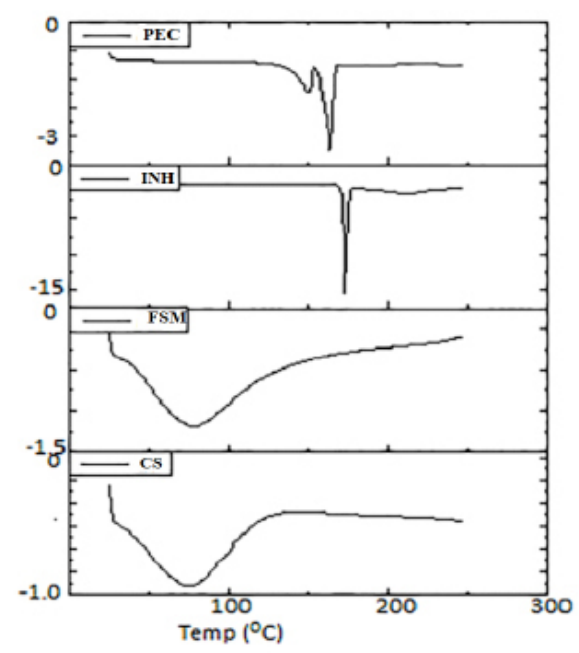

Figure 2. Thermogram of PEC, INH, FSM and CS

Figure 3 displays the X-ray diffraction spectra of PEC, CS, INH and FSM respectively. X-ray diffractogram of CS and FSM is of typical amorphous materials with no sharp peaks. The X-ray diffractogram of INH shows sharp peaks at $15.192^{\circ}, 16.344^{\circ}, 19.416^{\circ}, 24.84^{\circ}, 27.528^{\circ} 2 \Theta$ corresponding to its crystalline structure. However, X-ray pattern of PEC nanoparticles shows appearance of peaks $19.824^{\circ}, 24.84^{\circ}, 28.296^{\circ}, 36.024^{\circ}, 40.656^{\circ}, 45.672^{\circ} 2 \Theta$ that indicates crystalline nature of final product.

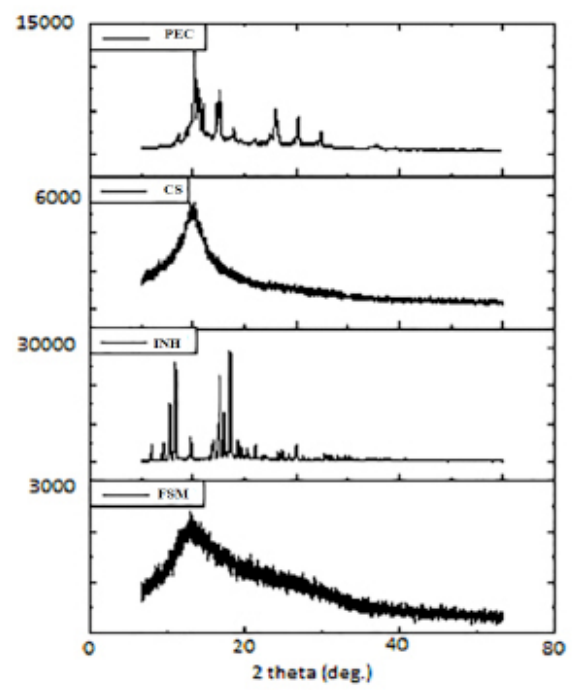

Figure 3. X-ray diffraction spectra of PEC, CS, INH and FSM 
Scanning electron microscopy is used to obtain information about the surface topography and composition. Fig. 4 displays the surface morphology of PEC nanoparticles scanned under scanning electron microscope (SEM). A close examination of surface morphology of INH loaded CS-FSM PEC nanoparticles reveals that surface of CS-FSM PEC nanoparticles is rough and granular.

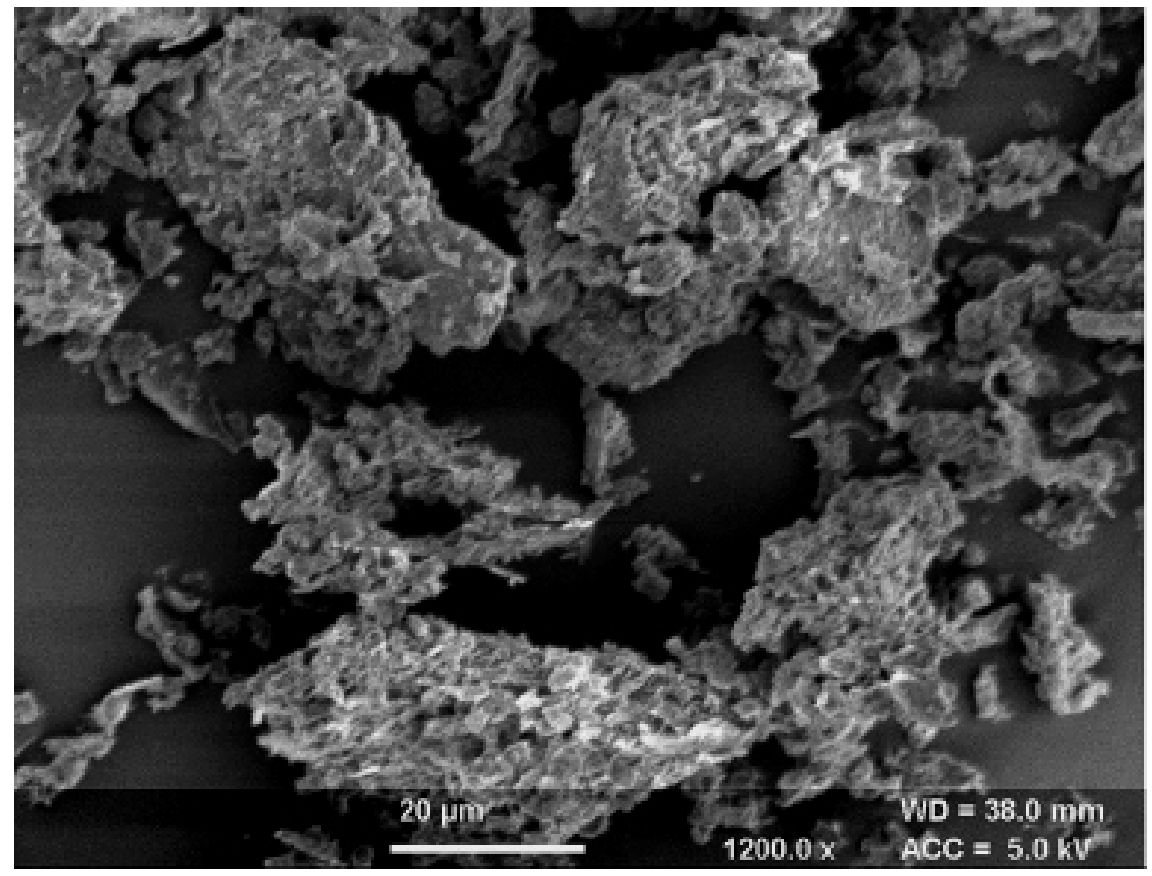

Figure 4. Surface morphology of PEC nanoparticles

Impact of critical process parameter and critical material attributes on the average particle size, PdI and entrapment efficiency of PEC nanoparticles between the FSM and CS was optimized for the formation of nanometric polyelectrolyte complex. The preliminary trial data suggested that concentration of chitosan and flax seed gum influence the p-size of polyelectrolyte particles and PdI. Accordingly, the concentration of chitosan $\left(\mathrm{X}_{1}\right)$ and FSM $\left(\mathrm{X}_{2}\right)$ were chosen as formulation variables whereas p-size $\left(\mathrm{Y}_{1}\right), \mathrm{PdI}\left(\mathrm{Y}_{2}\right)$ and entrapment efficiency $\left(\mathrm{Y}_{3}\right)$ were fixed as response variables to optimize the preparation of polyelectrolyte particles with constraints of minimum p-size and PdI and maximum entrapment efficiency of drug. Table 1 shows the result of $\mathrm{PS}\left(\mathrm{Y}_{1}\right), \operatorname{PdI}\left(\mathrm{Y}_{2}\right)$ and $\mathrm{EE}\left(\mathrm{Y}_{3}\right)$ of PEC nanoparticles prepared as per the design protocol. The response data was fitted into various polynomial models using the experimental design. It was discovered that the responses $\mathrm{PdI}\left(\mathrm{Y}_{2}\right)$ and entrapment efficiency $\left(\mathrm{Y}_{3}\right)$ were fitted best into linear model with none transformation while the response p- 
size $\left(\mathrm{Y}_{1}\right)$, was fitted best in to linear response surface model with square root transformation.

The polynomial models for the responses $\mathrm{Y}_{1}, \mathrm{Y}_{2}$ and $\mathrm{Y}_{3}$ can be expressed by the equation:

$$
\begin{aligned}
& \text { Sqrt }\left(Y_{1}\right)=21.22+2.91 X_{1}+0.9547 X_{2} \\
& \left(Y_{2}\right)=0.3314+0.1022 X_{1}+0.0368 X_{2} \\
& \left(Y_{3}\right)=87.85+2.35 X_{1}+0.8500 X_{2}
\end{aligned}
$$

The results of ANOVA are summarised in Table II. The polynomial model was found to be significant $(\mathrm{P}<0.0500)$ with non-significant lack of fit $(\mathrm{P}>0.05)$. The correlation between the experimental and predicted response is determined by the value of $\mathrm{R}^{2}(>0.8)$. This value indicated good correlation between the experimental and predicted response. The measurement of signal to noise ratio i.e. adequate precision is much above the required value of 4 indicating the adequate signal and lend the model fit to navigate the design space.

Table 2. Model summary statistics

\begin{tabular}{|c|c|c|c|c|c|c|c|}
\hline \multirow{2}{*}{$\begin{array}{c}\text { Response } \\
\text { factors }\end{array}$} & \multicolumn{5}{|c|}{ Model } & \multicolumn{2}{c|}{ Lack of fit } \\
\cline { 2 - 8 } & $\begin{array}{c}\text { F- } \\
\text { value } \\
(\%)\end{array}$ & $\begin{array}{c}\text { Prob.> } \\
\mathbf{f}\end{array}$ & $\mathbf{R}^{2}$ & $\begin{array}{c}\text { Adeq. } \\
\text { Prec }\end{array}$ & C.V. & $\begin{array}{c}\text { F- } \\
\text { value }\end{array}$ & Prob.>f \\
\hline$Y_{1}(\mathrm{PS})$ & 32.51 & 0.0001 & 0.8667 & 17.2978 & 4.38 & 4.78 & 0.0759 \\
\hline $\mathrm{Y}_{2}(\mathrm{Pdl})$ & 34.14 & 0.0001 & 0.8723 & 17.9753 & 9.72 & 0.9203 & 0.5592 \\
\hline $\mathrm{Y}_{3}(\mathrm{EE})$ & 24.20 & 0.0001 & 0.8288 & 15.1410 & 1.00 & 5.34 & 0.0635 \\
\hline
\end{tabular}
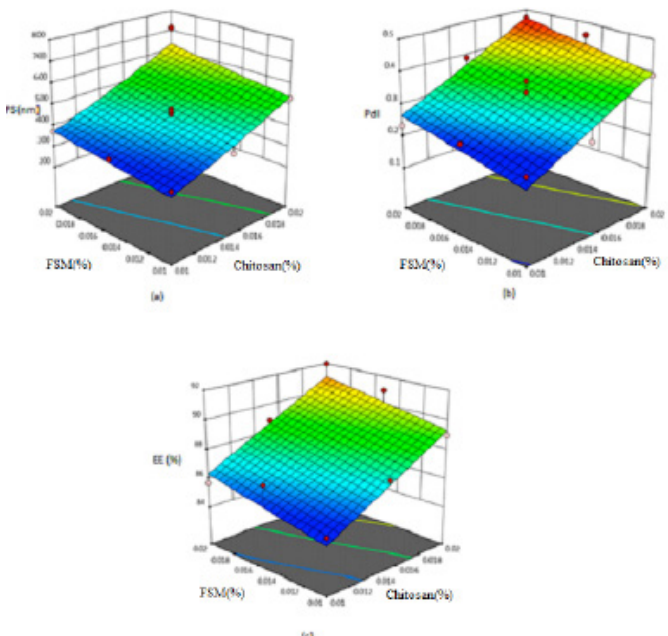

Figure 5. Effect of concentration of CS and FSM on (a) p-size, (b) Pdl and (c) entrapment efficiency (\%). 
Figure 5 (a,b,c) exhibits the combined effect of concentration of CS and FSM on p-size, PdI and entrapment efficiency (\%), respectively. It can be deduced from the plot that a linear relationship exists between dependent and independent variables. It is also observed from the plot that lower concentration of CS and FSM favors the lower particle size with more prominent effect of concentration of CS. This may be described by the fact that higher concentration of CS increases the viscosity of CS dispersion thus resulting in increased droplet size on spraying chitosan on FSM solution and thereby leading to increase in size of polyelectrolyte complex particles. To develop an optimized formulation of INH loaded PEC nanoparticles a numerical optimization technique along with desirability approach was used. The optimization of the CS/FSM concentration was done with the goal of preparing PEC nanoparticles with minimum particle size and minimum PdI and maximum entrapment efficiency. The optimization tool provided different sets of solution. An optimized batch of INH loaded PEC nanoparticle was prepared and analyzed for entrapment efficiency and in-vitro release. The recommended parameters were concentration of CS $(0.011 \% \mathrm{w} / \mathrm{v})$ and FSM (0.011 \%w/v) that dispensed INH loaded CS-FSM PEC nanoparticles of size $361 \mathrm{~nm}$ (predicted $326 \mathrm{~nm}$ ) and PdI 0.302 (predicted 0.217 ) and entrapment efficiency is $82.06 \%$ (predicted $85 \%$ ). The closer agreement between the predicted and observed values indicates the high prognostic/predictive ability of polynomial model. The optimized batch of INH loaded CS-FSM nano particulate system was evaluated for drug release behavior.

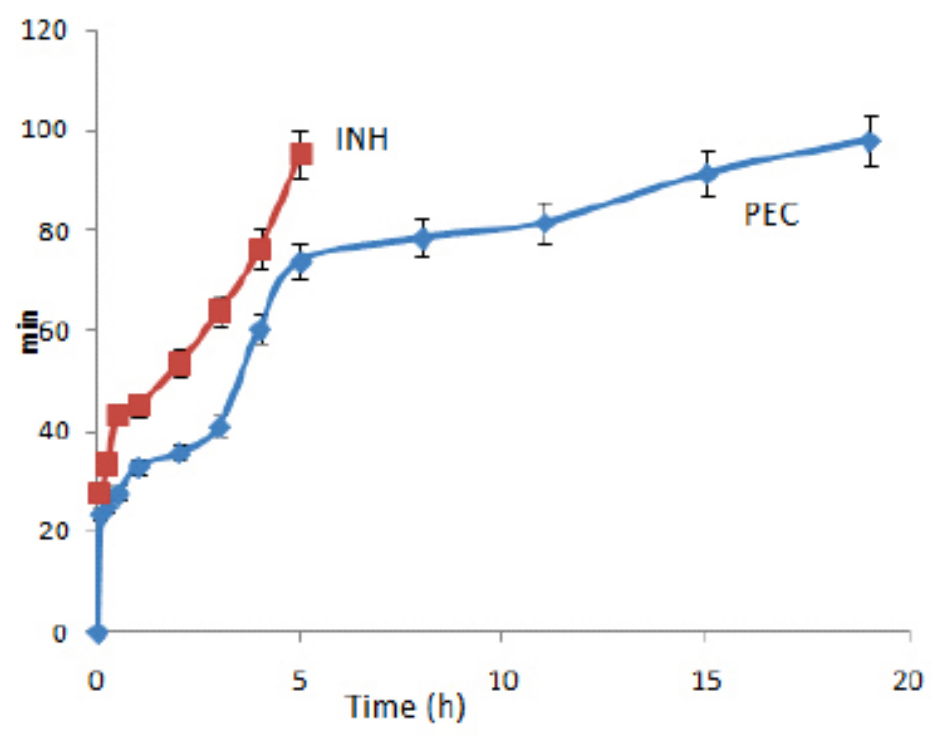

Figure 6. In vitro release profile of INH from polyelectrolyte complex and drug solution 
Figure 6 is displaying the in-vitro release profile of INH nanoparticulate system. The nanoparticulate preparation provided a prolonged release of INH with approximate $98 \%$ of drug released in a period of $20 \mathrm{~h}$. The limiting effect of dialysis membrane was studied by comparing the release behavior of nanoparticulate system with equivalent concentration of drug solution that showed more than $90 \%$ release in less than $5 \mathrm{~h}$. The release of INH from nanoparticulate system and from drug solution was fitted into various kinetic models to estimate their kinetics and mechanism of release mechanism (Table 3).

Table 3. Modeling and release kinetics of isoniazid from polyelectrolyte nano particulate suspension.

\begin{tabular}{|c|c|c|c|c|c|}
\hline \multirow{2}{*}{ Formulation } & \multirow{2}{*}{$\begin{array}{c}\text { Zero Order } \\
\mathbf{R}^{2}\end{array}$} & \multirow{2}{*}{$\begin{array}{c}\text { First Order } \\
\mathbf{R}^{2}\end{array}$} & \multirow{2}{*}{$\begin{array}{c}\text { Higuchi } \\
\mathbf{R}^{2}\end{array}$} & \multicolumn{2}{|c|}{ Korsemeyer - Peppas } \\
\hline & & & & $\mathbf{R}^{2}$ & $\mathbf{n}$ \\
\hline $\begin{array}{l}\text { Isoniazid } \\
\text { solution }\end{array}$ & 0.9021 & 0.4133 & 0.9857 & 0.3168 & 0.4787 \\
\hline PEC & 0.8938 & 0.4354 & 0.9658 & 0.3193 & 0.4512 \\
\hline
\end{tabular}

The outcomes of release rate data of the formulations were found to be fitted best into Higuchi model (with $\mathrm{R}^{2}=0.9658$ ) of release kinetics. Further the value of ' $n$ ' is $0.4512(0.43<n<0.85)$, the release exponent of korsemeyer and Peppas equation, indicated that the release of INH from nanoparticulate system occurs by diffusion and erosion mechanism from the matrix.

The interaction between cationic CS and anionic FSG was used to formulate polyelectrolyte complex. The DSC and XRD studies confirm the crystallinity of the product. The optimization study showed that lower level of chitosan (0.011\%) and flaxseed gum (0.011\%) favors the minimum particle size with more prominent effect of concentration of chitosan. The release of drug INH from PEC nanoparticles occurred over a prolonged period of time following Higuchi square root kinetics model and release occurs by mechanism of diffusion and erosion from the matrix. It can be concluded from the present study that interaction between chitosan and FSG can be used for the formation of PEC nanoparticles and for developing sustained release formulation.

\section{ACKNOWLEDGEMENTS}

The authors are thankful to Deptartment of Pharmaceutical sciences, Guru Jambheshwar University of Science \& Technology, Hisar for providing necessary facilities. 


\section{REFERENCES}

1. Dubey, S. D.; Srivastava, N.; Singh, P. K.; Narian, V. Genetic variability in yield and quality traits of linseed at different locations. J. Oilseed Res. 2009, 26, 161-163.

2. Goyal, A.; Sharma, V.; Upadhyay, N.; Gill, S.; Sihag, M. Flax and flaxseed oil: an ancient medicine and modern functional food. J. Food Sci. Technol. 2014, 51, 1633-1653.

3. Greenwald, P.; Clifford, C. K.; Milner, J. A. Diet and cancer prevention. Eur. J. Cancer, 2001, 37, 948-965.

4. Kristensen, M.; Jensen, M. G.; Aarestrup, J.; Petersen, K. E.; Søndergaard, L.; Mikkelsen, M. S.; Astrup, A. Flaxseed dietary fibers lower cholesterol and increase fecal fat excretion, but magnitude of effect depend on food type. Nutr. Metab. 2012, 9,8 .

5. Touré, A.; Xueming, X. Flaxseed lignans: source, biosynthesis, metabolism, antioxidant activity, bio-active components, and health benefits. Compr. Rev. Food Sci. F. 2010, 9, 261-269.

6. Avadi, M. R.; Sadeghi, A. M. M.; Mohammadpour, N.; Abedin, S.; Atyabi, F.; Dinarvand, R.; Rafiee-Tehrani, M. Preparation and characterization of insulin nanoparticles using chitosan and Arabic gum with ionic gelation method. Nanomedicine: NBM, 2010, 6, 58-63.

7. Bhatia, M.; Ahuja, M. Psylliumarabinoxylan: Carboxymethylation, characterization and evaluation for nanoparticulate drug delivery. Int. J. Biol. Macromol. 2015, 72, 495-501.

8. Lim, S. T.; Martin, G. P.; Berry, D. J.; Brown, M. B. Preparation and evaluation of the in vitro drug release properties and mucoadhesion of novel microspheres of hyaluronic acid and chitosan. J. Control. Release, 2000, 66, 281-292.

9. Kumar, A.; Ahuja, M. Carboxymethyl gum kondagogu-chitosan polyelectrolyte complex nanoparticles: Preparation and characterization. Int. J. Biol. Macromol. 2013, 62, 80-84.

10. Thakur, K.; Ahuja, M.; Kumar, A. Carboxymethyl functionalization of amylopectin and its evaluation as a nanometric drug carrier. Int. J. Biol. Macromol. 2013, 62, 25-29.

11. Ahuja, M.; Kumar, A. Gum ghatti-chitosan polyelectrolyte nanoparticles: Preparation and characterization. Int. J. Biol. Macromol. 2013, 61, 411-415.

12. Motwani, S. K.; Chopra, S.; Talegaonkar, S.; Kohli, K.; Ahmad, F. J.; Khar, R. K. Chitosansodium alginate nanoparticles as submicroscopic reservoirs for ocular delivery: Formulation, optimisation and in vitro characterisation. Eur. J. Pharm. Biopharm. 2oo8, 68, 513-525.

13. Lougheed, K. E.; Taylor, D. L.; Osborne, S. A.; Bryans, J. S.; Buxton, R. S. New anti-tuberculosis agents amongst known drugs. Tuberculosis, 2009, 89, 364-370.

14. Becker, C., Dressman, J.B., Amidon, G.L., Junginger, H.E., Kopp, S., Midha, K.K., Shah, V.P., Stavchansky, S., Barends, D.M. (2007). Biowaiver Monographs for Immediate Release Solid Oral Dosage Forms: Isoniazid. J. Pharm. Sci. 2007, 96, 522-531. 